\title{
Fracture of a Modular Femoral Neck After Total Hip Arthroplasty
}

\author{
A Case Report \\ By Commander Geoffrey Wright, MD, Scott Sporer, MD, MS, Robert Urban, PhD, and Joshua Jacobs, MD \\ Investigation performed at the Department of Orthopedics, Rush University Medical Center, Chicago, Illinois
}

\section{$\mathrm{T}$} he use of modularity in femoral stem designs for total hip arthroplasty has increased substantially over the past several years. The theoretical advantages of this design include the optimization of femoral anteversion, limb length, and offset of the femoral component. We report on a previously unreported fracture of a modular femoral neck device.

The patient was informed that data concerning the case would be submitted for publication, and he consented.

\section{Case Report}

A forty-nine-year-old man underwent a primary total hip A arthroplasty of the left hip, in June 2005, because of degenerative osteoarthritis and received a size-4 PROFEMUR Z femoral stem (Wright Medical Technology, Arlington, Tennessee) and a 64-mm CONSERVE acetabular component (Wright Medical Technology). The patient was $6 \mathrm{ft} 6$ in $(198 \mathrm{~cm})$ tall and weighed $340 \mathrm{lb}(154.2 \mathrm{~kg})$. An anterolateral surgical approach was utilized, and the bearing surface chosen was metal on metal. This proximal femoral cementless component is a dual-tapered rectangular stem that has a modular neck. The modular neck has an oval taper distally that is inserted into the femoral stem at a fixed angle. This allows the surgeon to independently adjust the offset and length as it is available in six different neck geometries and two lengths. Five different head options, ranging from $-3.5 \mathrm{~mm}$ to $+10.5 \mathrm{~mm}$, are also available with this design. The head and neck are connected by means of a standard 12/14 Morse taper. Both the femoral stem and the modular neck are manufactured from a titanium alloy (Ti-6Al-4V). The patient had a $56-\mathrm{mm}$ head with a $-3.5-\mathrm{mm}$ neck length. The neck geometry was a long varus anteverted neck (AR/VV2). The patient was otherwise healthy. The postoperative course was uneventful, and he was pain-free within three months after the procedure.

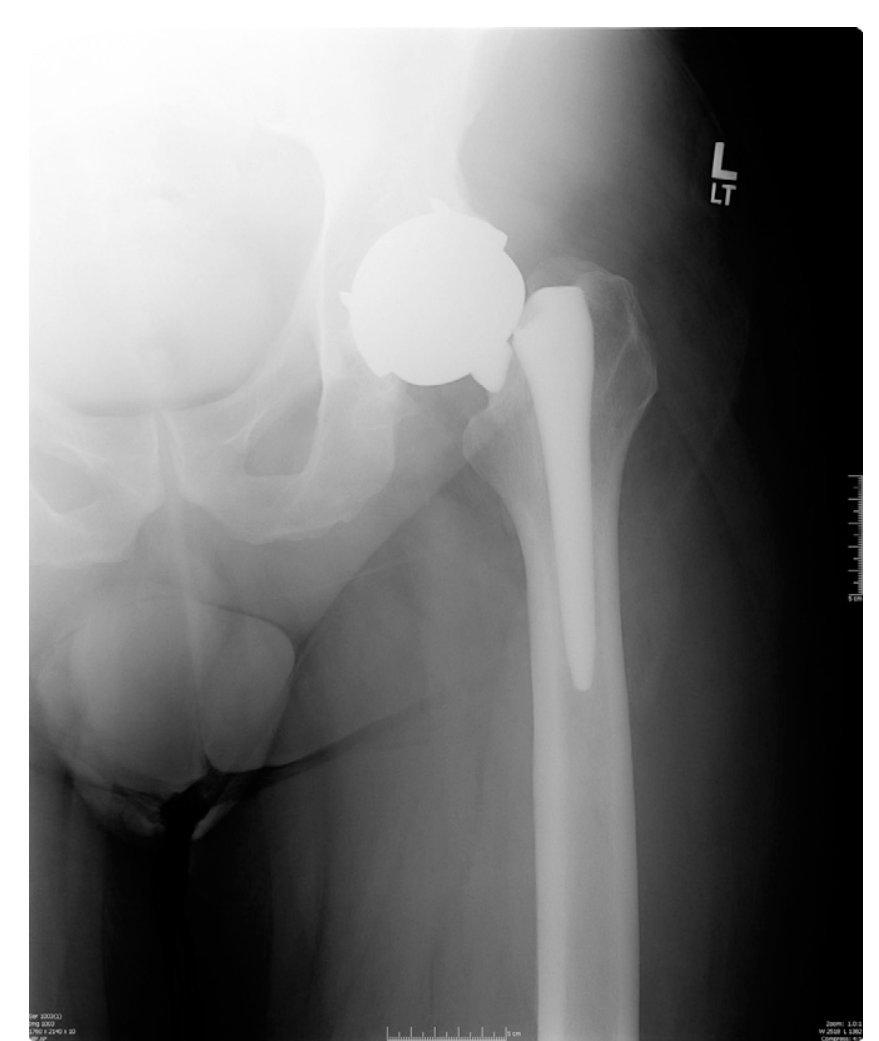

Fig. 1

Anteroposterior radiograph of the left hip made at the time of presentation four years after total hip arthroplasty and two months after a fall. Note that the femoral stem is not in contact with the neck and instead appears to be in contact with the femoral head. The proximal portion of the neck appears to be in contact with the medial calcar.

Disclosure: In support of their research for or preparation of this work, one or more of the authors received, in any one year, outside funding or grants in excess of $\$ 10,000$ from Zimmer and the National Institutes of Health (Grant AR39310). One or more of the authors, or a member of his or her immediate family, received, in any one year, payments or other benefits in excess of $\$ 10,000$ or a commitment or agreement to provide such benefits from commercial entities (Zimmer and Medtronic).

Disclaimer: The views expressed in this article are those of the author and do not necessarily reflect the official policy or position of the Department of the Navy, Department of Defense, or the U.S. Government. One author is a military service member serving at Naval Medical Center Portsmouth. This work was prepared as part of his official duties. Title 17 U.S.C. $\$ 105$ provides that "Copyright protection under this title is not available for any work of the United States Government." Title 17 U.S.C. $\$ 101$ defines a U.S. Government work as work prepared by a military service member or employee of the U.S. Government as part of that person's official duties. 
The Journal of Bone \& Joint Surgery · Jbjs.org Volume 92-A • Number 6 J June 2010

In January 2009 (four years postoperatively), the patient slipped on ice and fell directly onto the left hip. Following the fall, he reported no pain or discomfort but noticed a new onset of clicking and squeaking coming from the hip. Approximately two months later, three days before presentation to our office, he leaned over to tie his shoes, heard a snap, and was unable to bear weight on the left lower extremity. Radiographs made at that time demonstrated well-fixed acetabular and femoral components with a fracture of the modular neck (Fig. 1). The femoral head remained well fixed to the proximal fragment of the modular neck, while the distal fragment of the modular neck remained seated in the bore of the femoral stem.

He was referred to our institution, where he underwent a revision total hip arthroplasty. Preoperative laboratory testing was not suggestive of an infection, with an erythrocyte sedimentation rate of $23 \mathrm{~mm} / \mathrm{hr}$ (normal, 0 to $9 \mathrm{~mm} / \mathrm{hr}$ ) and a Creactive protein level of $2.3 \mathrm{mg} / \mathrm{L}$ (normal, 0 to $1.0 \mathrm{mg} / \mathrm{L}$ ). No metal ion serum levels were obtained. A posterior approach was used to expose the hip. Intraoperative cell count and frozensection results showed no signs of infection. The modular neck was confirmed to be fractured near the neck-stem junction. The head and proximal aspect of the neck were removed from the wound. It was not possible to independently remove the distal aspect of the femoral neck from the stem; therefore, the stem extractor could not be used (Fig. 2). An extended tro-

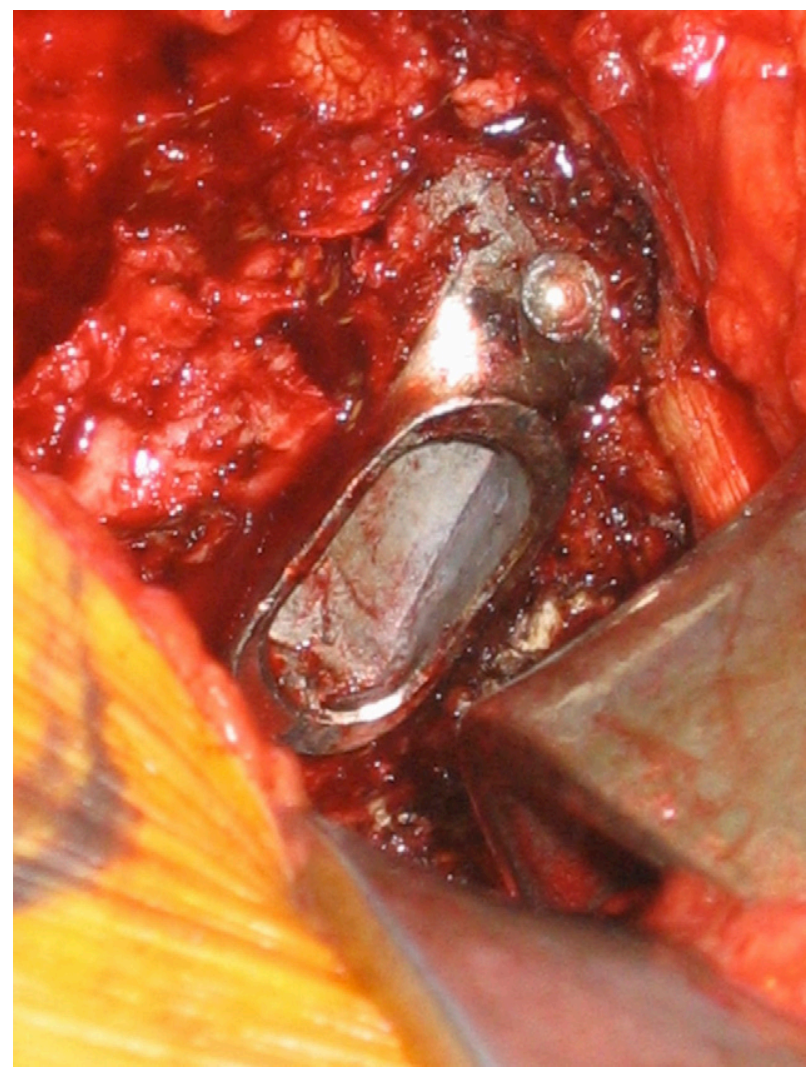

Fig. 2

Intraoperative photograph of the femoral stem and the distal aspect of the neck embedded in the femoral canal.
Fracture of a Modular femoral Neck After

TOTAL Hip ARTHROPLASTY

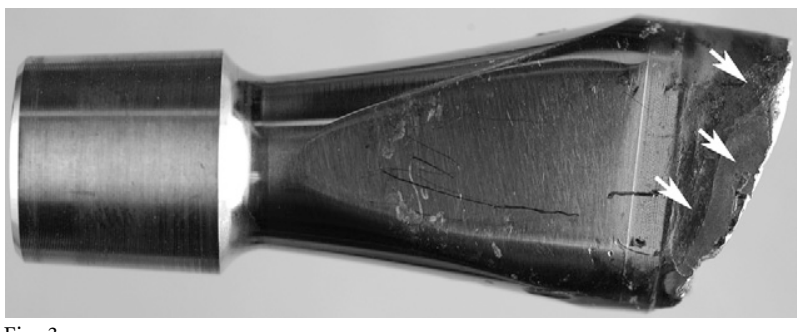

Fig. 3

The retrieved modular neck demonstrates fretting and corrosion damage (arrows) on the surface that had mated with the femoral stem.

chanteric osteotomy was performed, and the femoral stem and fractured distal fragment of the modular neck were removed en bloc. The acetabular cup was removed with the explant device because of incompatibility between the acetabular component and the new femoral head. The hip was reconstructed with a 66-mm modular trabecular metal cup (Zimmer, Warsaw, Indiana) and 6-in $(15.2-\mathrm{cm})$ VerSys FullCoat stem (Zimmer) with a $40-\mathrm{mm}$ head. The extended trochanteric osteotomy was repaired with cables. Cultures at the time of surgery showed no growth.

Examination of the distal fragment of the modular neck with use of light microscopy showed marked fretting and corrosion damage and black fretting with corrosion debris (Fig. 3). The damage was concentrated on the lateral and anterior surfaces where they had mated with the stem. Scanning electron microscopy revealed severe corrosion, consisting of scalloping and pitting of the mating surfaces (Fig. 4). The fracture surface demonstrated a clear clamshell pattern characteristic of a fatigue fracture radiating from the corroded area on the anterolateral surface of the modular neck. Neither fretting nor corrosion damage was evident at the modular head-neck junction.

\section{Discussion}

odular hip systems have gained popularity as they offer 1 the surgeon the potential to restore normal hip biomechanics with the ability to independently adjust offset, version, and limb length. However, there are concerns that with any metal-on-metal modular junction, there is the potential for fretting corrosion and concomitant metal ion release.

Fracture of femoral components is a rare complication in total hip arthroplasty. Prior to the introduction of forged cobalt-chromium molybdenum and titanium alloys, Charnley estimated the stem fracture prevalence to be $0.23 \%{ }^{1}$, while other designs may have been as high as $11 \%^{2}$. Fractures of the neck of the femoral stem have been reported. Factors contributing to fracture include defects in welding of the neck to the prosthesis ${ }^{3}$, heavy laser etching in the region ${ }^{4}$, and crevice corrosion associated with the head-neck junction ${ }^{5,6}$.

In vitro studies of femoral components with neck-stem modularity have shown that corrosion and fretting can occur at the neck-stem junction and that this occurs primarily at the medial contact point between the neck and $\mathrm{stem}^{7,8}$. 


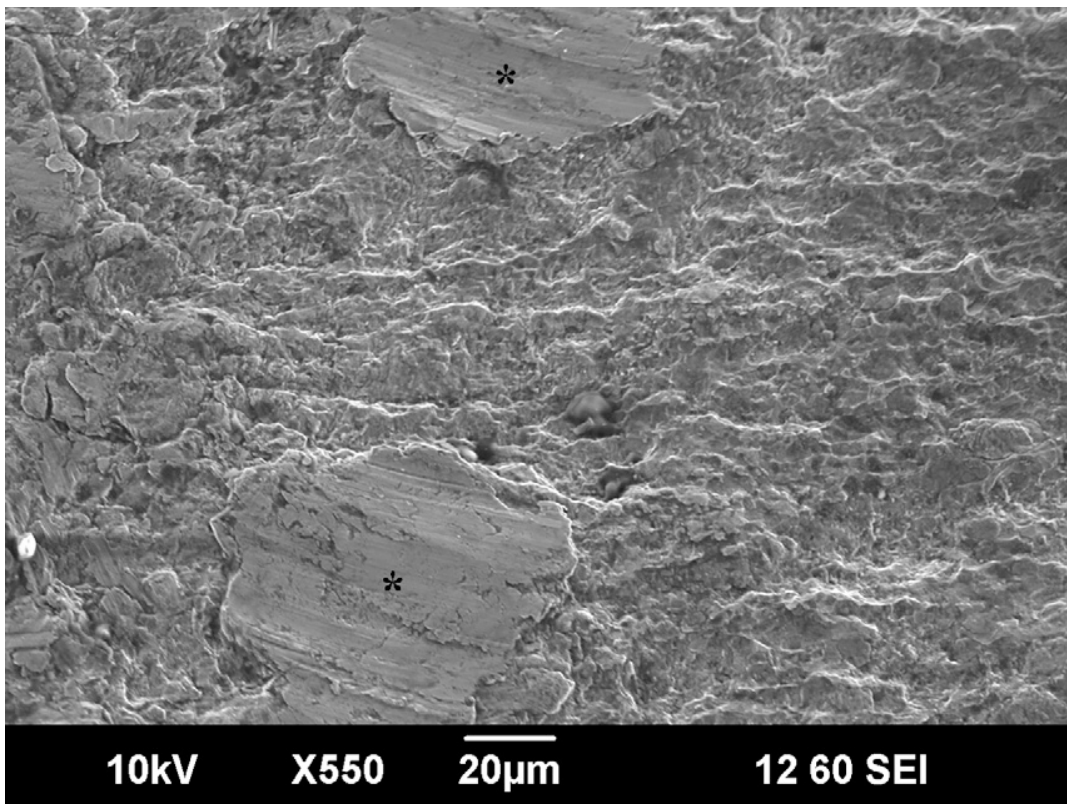

Fig. 4

Scanning electron microscopy of the lateral aspect of the mating surface reveals severe corrosion, consisting of scalloping and pitting. The asterisks indicate the original implant surface.

Retrieval studies by Kop and Swarts 9 showed that corrosion and fretting occur at both the head-neck and the neckstem modular junctions. Longer implantation times increase the amount of corrosion and fretting. They also reported that the degradation of the neck-stem junction was more significant than at the head-neck junction and was believed to be secondary to the increased lever arm and high mechanical stress. Inflammatory mediators are released as a consequence of the cellular response to the particulate and/or ionic products of fretting and corrosion. This can ultimately result in the need to revise the prosthesis ${ }^{10,11}$.

Recently, Varini et al. reported that stem impactors that secure the femoral stem by means of the neck-stem junction induce some damage to the bore of the femoral stem. They hypothesized that this may trigger increased fretting damage resulting in the production of debris ${ }^{12}$. It is not known whether this type of impactor was used in the index procedure in this patient. An alternative impactor that does not engage the neck-stem junction is available for insertion of the femoral stem.

Case reports of dissociation of modular hip stem prosthesis have been published ${ }^{13-15}$, and there is one case of a patient who had dissociation of the Alpha II (Osteoimplant Technology, Hunt Valley, Maryland) fully porous-coated stem ${ }^{16}$. The difference between the Alpha II and the implant used in our patient is that the neck-stem junction is much deeper in the implant in the present report. This stem also has demonstrated excellent success, with clinical results at ten years showing no complications with fracture of the modular necks ${ }^{17-19}$.

This implant had a long varus modular neck. The lever arm, combined with the height and weight of the patient, probably resulted in increased stresses at the neck-stem modular junction. While it is impossible to be certain, we believe that the body habitus of the patient along with the long varus neck contributed to the finding of substantial fretting and corrosion, and subsequent neck fracture.

Commander Geoffrey Wright, MD

Scott Sporer, MD, MS

Robert Urban, $\mathrm{PhD}$

Joshua Jacobs, MD

Department of Orthopedics,

Rush University Medical Center,

1725 West Harrison Street,

Suite 1063, Chicago, IL 60612.

E-mail address for G. Wright:

geoffrey.wright@med.navy.mil

\section{References}

1. Charnley J. Fracture of femoral prostheses in total hip replacement. A clinical study. Clin Orthop Relat Res. 1975;111:105-20.

2. Martens $M$, Aernoudt E, de Meester $P$, Ducheyne $P$, Mulier JC, de Langh $R$, Kestelijn P. Factors in the mechanical failure of the femoral component in total hip prosthesis. Report of six fatigue fractures of the femoral stem and results of experimental loading tests. Acta Orthop Scand. 1974;45:693-710.

3. Aspenberg $\mathrm{P}$, Kolmert L, Persson L, Onnerfält R. Fracture of hip prostheses due to inadequate welding. Acta Orthop Scand. 1987;58:479-82. 
The Journal of Bone \& Joint Surgery $\cdot$ Jbjs.org VOLUme 92-A • Number 6 J June 2010

4. Lee EW, Kim HT. Early fatigue failures of cemented, forged, cobalt-chromium femoral stems at the neck-shoulder junction. J Arthroplasty. 2001;16:236-8.

5. Gilbert JL, Buckley CA, Jacobs JJ, Bertin KC, Zernich MR. Intergranular corrosionfatigue failure of cobalt-alloy femoral stems. A failure analysis of two implants. J Bone Joint Surg Am. 1994;76:110-5.

6. Botti TP, Gent J, Martell JM, Manning DW. Trunion fracture of a fully porous-coated femoral stem. Case report. J Arthroplasty. 2005;20:943-5.

7. Viceconti M, Baleani M, Squarzoni S, Toni A. Fretting wear in a modular neck hip prosthesis. J Biomed Mater Res. 1997;35:207-16.

8. Viceconti M, Ruggeri O, Toni A, Giunti A. Design-related fretting wear in modular neck hip prosthesis. J Biomed Mater Res. 1996;30:181-6.

9. Kop AM, Swarts E. Corrosion of a hip stem with a modular neck taper junction: a retrieval study of 16 cases. J Arthroplasty. 2009;24:1019-23.

10. Jones DM, Marsh JL, Nepola JV, Jacobs JJ, Skipor AK, Urban RM, Gilbert JL, Buckwalter JA. Focal osteolysis at the junctions of a modular stainless-steel femoral intramedullary nail. J Bone Joint Surg Am. 2001;83:537-48.

11. Lee SH, Brennan FR, Jacobs JJ, Urban RM, Ragasa DR, Glant TT. Human monocyte/macrophage response to cobalt-chromium corrosion products and titanium particles in patients with total joint replacements. J Orthop Res. 1997;15: 40-9.
Fracture of a Modular femoral Neck After

TOTAL Hip ARTHROPLASTY
12. Varini $E$, Cristofolini $L$, Viceconti $M$, Traina F. Stem damage during implantation of modular hip prostheses. Artif Organs. 2006;30:564-7.

13. Chu CM, Wang SJ, Lin LC. Dissociation of modular total hip arthroplasty at the femoral head-neck interface after loosening of the acetabular shell following hip dislocation. J Arthroplasty. 2001;16:806-9.

14. Fanuele J, Bernini P. Dissociation of the modular femoral stem from the metaphyseal sleeve during reduction of a total hip arthroplasty dislocation. J Arthroplasty. 2007;22:140-2.

15. Patel A, Bliss J, Calfee RP, Froehlich J, Limbird R. Modular femoral stem-sleeve junction failure after primary total hip arthroplasty. J Arthroplasty. 2009;24:1143.e1-5.

16. Sporer SM, DellaValle C, Jacobs J, Wimmer M. A case of disassociation of a modular femoral neck trunion after total hip arthroplasty. J Arthroplasty. 2006;21: 918-21.

17. Köster G, Walde TA, Willert HG. Five- to 10 -year results using a noncemented modular revision stem without bone grafting. J Arthroplasty. 2008;23:964-70.

18. Antonietti B, Paderni S, Sama D, Comitini V, Sudanese A. Anatomic cementless total hip arthroplasty with ceramic bearings and modular necks: 3 to 5 years followup. Chir Organi Mov. 2003;88:259-65.

19. Toni A, Sudanese A, Paderni S, Guerra E, Bianchi G, Antonietti B, Giunti A. Cementless hip arthroplasty with a modular neck. Chir Organi Mov. 2001;86:73-85. 